\title{
Animals Speaking in the Fiction of Jin and Malamud
}

\author{
Matt Prater \\ Appalachian State University
}

Follow this and additional works at: https://docs.lib.purdue.edu/clcweb

ర

Part of the American Studies Commons, Comparative Literature Commons, and the Reading and Language Commons

Dedicated to the dissemination of scholarly and professional information, Purdue University Press selects, develops, and distributes quality resources in several key subject areas for which its parent university is famous, including business, technology, health, veterinary medicine, and other selected disciplines in the humanities and sciences.

CLCWeb: Comparative Literature and Culture, the peer-reviewed, full-text, and open-access learned journal in the humanities and social sciences, publishes new scholarship following tenets of the discipline of comparative literature and the field of cultural studies designated as "comparative cultural studies." Publications in the journal are indexed in the Annual Bibliography of English Language and Literature (Chadwyck-Healey), the Arts and Humanities Citation Index (Thomson Reuters ISI), the Humanities Index (Wilson), Humanities International Complete (EBSCO), the International Bibliography of the Modern Language Association of America, and Scopus (Elsevier). The journal is affiliated with the Purdue University Press monograph series of Books in Comparative Cultural Studies. Contact: <clcweb@purdue.edu>

\section{Recommended Citation}

Prater, Matt. "Animals Speaking in the Fiction of Jin and Malamud." CLCWeb: Comparative Literature and Culture 15.4 (2013): <https://doi.org/10.7771/1481-4374.2054>

This text has been double-blind peer reviewed by $2+1$ experts in the field.

The above text, published by Purdue University Press @P Purdue University, has been downloaded 757 times as of $11 /$ $07 / 19$.

This document has been made available through Purdue e-Pubs, a service of the Purdue University Libraries. Please contact epubs@purdue.edu for additional information.

This is an Open Access journal. This means that it uses a funding model that does not charge readers or their institutions for access. Readers may freely read, download, copy, distribute, print, search, or link to the full texts of articles. This journal is covered under the CC BY-NC-ND license. 


\section{PURDUE}

U N I V E R S I T Y UNIVERSITY PRESS < http://www.thepress.purdue.edu>

\section{CLCWeb: Comparative Literature and Culture}

ISSN 1481-4374 <http://docs.lib.purdue.edu/clcweb> Purdue University Press @Purdue University

CLCWeb: Comparative Literature and Culture, the peer-reviewed, full-text, and open-access learned journal in the humanities and social sciences, publishes new scholarship following tenets of the discipline of comparative literature and the field of cultural studies designated as "comparative cultural studies." In addition to the publication of articles, the journal publishes review articles of scholarly books and publishes research material in its Library Series. Publications in the journal are indexed in the Annual Bibliography of English Language and Literature (Chadwyck-Healey), the Arts and Humanities Citation Index (Thomson Reuters ISI), the Humanities Index (Wilson), Humanities International Complete (EBSCO), the International Bibliography of the Modern Langua-ge Association of America, and Scopus (Elsevier). The journal is affiliated with the Purdue University Press monog-raph series of Books in Comparative Cultural Studies. Contact: <clcweb@purdue.edu>

\begin{tabular}{c} 
Volume 15 Issue 4 (December 2013) Article 1 \\
Matt Prater, \\
"Animals Speaking in the Fiction of Jin and Malamud" \\
<http://docs.lib.purdue.edu/clcweb/vol15/iss4/1> \\
\hline Contents of CLCWeb: Comparative Literature and Culture 15.4 (2013) \\
<http://docs.lib.purdue.edu/clcweb/vol15/iss4/>
\end{tabular}

Abstract: In his article "Animals Speaking in the Fiction of Jin and Malamud" Matt Prater discusses "The Jewbird" by Bernard Malamud and "A Composer and His Parakeets" by Ha Jin as transcultural texts which involve non-human animals as major characters. Jin and Malamud examine differing representations of animal language and how these representations connect to the politics of both interspecies and transnational relationships. By applying critical animal studies and transnational discourse and by charting the interlinking of other-ings by theorists such as Carol Adams and Susan Kappeler, Prater attempts to show that animals figure into transcultural and transnational discourses in ways other than the symbolic. 


\section{Matt PRATER}

\section{Animals Speaking in the Fiction of Jin and Malamud}

There are a number of similarities between the works of Ha Jin's (金雪飛) and Bernard Malamud's works which suggest comparative study of their fiction, especially their short stories. Both are writers who, to apply to both Jerry A. Varsava's statement with regard to Jin that the "prose style [suggest] a constrained realism that derives largely from [their] early exposure to the great Russian writers of the nineteenth century ... but also from the profound challenge of writing in a borrowed idiom" (2). The idioms they inhabit may be different, of course: for Jin, it is his English, his second language, acquired during the process of his immigration from China to the United States and for Malamud, it is the Yiddish-inflected English of East European Jewish American immigrants of the generation preceding his own. Yet what holds true for both writers is that they are writing from a space that can be considered transcultural, if not always (in Malamud's case) transnational. Both writers have stories which deal with the underbellies of immigrant experience and the problematic scripts of US-Americanization, both have written about the experiences of specific ethnic communities in specific locations in New York City, and both have written extended animal fables which involve transformative relationships between humans and animals.

I am positing the above because it may seem obvious, almost inevitable, that a study of these writer's stories, especially in conjunction, would remain centered on humanistic issues. But the moral landscape of both writers and their focus on the oppressed and marginalized allows for readings which expand beyond human ethical considerations and take in the experiences of other groups, particularly non-human animals. As Jin writes, although a writer's political gestures "must be secondary, and he should be aware of the limits of his art as social struggle," there also exists a deep ethical responsibility for the writer, and therefore "There is no argument that the writer must take a moral stand and speak against oppression, prejudice, and injustice" (The Writer 29). In Critical Animal Studies (CAS), the oppression of animals is part of an interconnected web of oppressions which involves the devaluing of many othered groups, both non-human and human. This interconnectedness of subjugation is probably most clearly explained by activist and theorist Carol J. Adams, who concludes in her book Neither Man nor Beast: Feminism and the Defense of Animals that "focusing attention on how oppressions interconnect creates the space for raising the issue of animals" (79). This is more than saying that animal oppression is a mirror for the ways humans mistreat each other: for the critical animal scholar, the beings and lives of animals contain value in their own rights. Nevertheless, one can read, as Susan Kappeler has, a distinct connection between "Speciesism, Racism [and] Nationalism." One of the metaphors Kappeler draws on in her work and one which fits particularly well with the following reading of Jin's and Malamud's fictions is that of an "International Zoo of Nations": "The idea of an international community of nations is akin to that of a zoo, with species separated into their respective territories - by they cages or reservations. It is a measure that has its appeal at a point where so many species (and communities) are indeed threatened by extinction, so that a cage in a zoo appears like the last protection from final aggression. Yet the zoo has been established and is being maintained precisely by those responsible for the extinction of species in the first place" (342; on animals in literature, see, e.g., DeMello; Malamud, Randy <http://dx.doi.org/10.7771/1481-4374.1072>).

Although Kappeler's main point is to describe how the neocolonial construct of the nation-state is an ethnically reductive and racially essentializing institution that upholds a male Eurocentric (i.e., including the U.S.) hegemony and how this model repeats itself in humans' treatment of nonhumans, thus showing her concern with connecting the reader's understanding of oppression at the interhuman and interspecies levels, connections can still be made between this broader diagnosis and the essentially domestic landscapes of the fictions in question. Because - although scholars like Kappeler and Adams would not accept a reading of human oppression of animals as a symbolic phenomenon as to cast animals as mere symbols would be to deny their interiority - it is entirely possible to perform a reading of human treatment of animals that both illustrates the broader pattern of people's oppressive activities toward each other and upholds the people-ness of the animals described in a specific instance of interspecies subjugation. Considering the interconnected 
understanding of oppression that Kappeler and Adams describe can inform a critical understanding of Jin's and Malamud's work. The type of identity politics is slightly different in each of their stories: while in Jin's "A Composer and His Parakeets" - because of Fanlin's lover's international work life and because of the immigrant nature of Fanlin's hometown of Flushing, New York - the story's ethnic politics are mostly transnational in nature, in Malamud's "The Jewbird" the self-contained setting of the story and the fact that the human family of the story is caught up in acting out a particularly complicated script of US-Americanization. That is, they are U.S.-born Jews attempting to pass as culturally white and Malamud's ethnic politics are mostly racial rather than national. That said, characters in both writers' stories are caught up in lies they are telling about themselves and in both writers' stories the catalyst for a critical examination of these lies comes through the person of a non-human animal.

My brief introduction in presenting the lens of critical animal studies as interested in the reclamation of non-human animals from invisibility and oppression should not be taken to mean that my key goal is to highlight only the ways in which animal oppression is portrayed and counteracted in the texts although in the case of Malamud's "The Jewbird," violence performed upon the Jewbird, Mr. Schwartz, does form an integral part of the story. Rather, my point is to highlight the potential this lens has for highlighting animals' particularity and interiority as a key locus of meaning in the stories. Further, beyond understanding how a study of animal mistreatment informs our understanding of human othering as a whole, I am interested in examining how interspecies communication allows humans in each story to overcome their initial limitations.

The two stories follow different patterns of representing animal speech. In "The Jewbird," as in all of Malamud's animal fiction, he follows the typical pattern of magical realism by anthropomorphically giving the Jewbird the ability to communicate in English. Yet, because Malamud focuses so on the particularities of Schwartz's bodily life as a bird addressing the fears, needs, and desires which come out of bird experience and because the narrator highlights Schwartz's dignified response to what is always a connectedly doubled othering - not Jew and bird, but Jewbird - Malamud avoids making his anthropomorphic treatment anthropocentric. In the same light, but using a considerably different technique, Jin constructs a story in which a Chinese American composer's capacity for empathy (and his ability to compose emotionally resonant music) is catalyzed by his relationships with parakeets. In addition to being less about animal mistreatment than Malamud's story what makes Jin's construction of animal speech different from Malamud's is that there are no magical elements to the story: Bori and Devin, the birds of the story, speak the way living birds actually do and the one seemingly magical moment in the story can also be explained in completely natural terms. The more orthodox model of interspecies communication is the anthropomorphic model contained in Malamud's "The Jewbird," the first of Malamud's three texts about non-human animals the second being his short story "Talking Horse," and the last being his last completed novel, God's Grace. All three stories involve animals which have the capacity for human speech: a bird in the first, a horse in the second, and a group of nonhuman primates the third and in each story the reasoning for speech is more fully explained than in the preceding tale. In God's Grace, the chimpanzee Buz is able to speak after first being trained "in learning the Amelesan sign language for the deaf" (20) and then by undergoing surgery to alter his voice box. After coming under the protection of Calvin Cohn - assistant to Bud's former owner and the last living human on earth (the plot of the novel involves a post apocalyptic world in which Cohn transfers responsibility for 'human' culture to non-human primates) - Buz finally manages to manipulate the voice box and later to teach the other living chimps and gorillas to speak: "Though Cohn, as scientist, could not understand how the chimps had learned to speak English, he was of course gratified that they had learned. If explanation was different: the world was different that it once was; and what might happen, and what could not, he was not as sure of as he used to be" (107).

The implication of the above passage and why it matters for a study of the former story is that immediately after a chimp has taught a human language to other chimps and gorillas, the only human being present, who actually taught neither Buz nor any of the other speakers how to speak English, attempts to take credit for the event or at least to explain the occurrence away. Cohn attempts to teach the chimps an anthropocentric form of Judaism in which he serves as a type of 
Moses figure, but as the reader learns in the descriptions of god in the story, he is "invisible; light from which a voice extruded; no sign of Godcrown, silver beard, peering eye - the image in which man had sought his own" (6). In the world that Buz and the other chimps inhabit, god is neither man nor beast and the distinction between man and beast as a binary of sentient author and subconscious entity is dismantled. In fact, the novel ends with chimps and gorillas having transmogrophied Cohn's religion for their own use and in the final scenes of the work the primates kill Cohn as a ritual sacrifice: "Cohn lay still on the floor of the cave waiting to be lifted onto the flames. By the golden dark-light of the fire he could see that his long white beard was flecked with spots of blood. 'Merciful God,' he said, 'I am an old man. The Lord has let me live my life out.' He wept at the thought. Maybe tomorrow the world to come? In a tall tree in the valley below, George the gorilla, wearing a mud-stained white yarmulke he had one day found in the woods, chanted, 'Sh'ma, Yisroel, the Lord our God is one.' In his throaty, gruff voice he began a long Kaddish for Calvin Cohn" (223). Lines are blurred between humans and non-humans, mostly by showing the ways that animal people act like human people. However, while these portraits are rendered using largely anthropomorphic techniques, the effect on the reader is to suggest a broadening of imaginative sympathies. As the protagonist proposes in the opening of "Talking Horse," the ability to speak as a human leads him to question whether he is "a man in a horse or a horse that talks like a man" (514). And although he eventually comes to a position of compromise, living as "a free centaur" (530), the fact that he asks the question at all points toward the conclusion that it is selfawareness rather than membership in any particular species and that is the ultimate marker of personhood (530). The phrase "free centaur" does offer a rather limited conclusion for the scholar interested in claiming the inherent sentience and self-determinism of non-human animals as that model of hybridity suggests an infungibility between the forms of human and beast which can only be bridged in a miraculous circumstance and thus, by consequence, it reinforces the position that in the real world language (and, by extension, conscience) are only contained in the human. The notion opens the ground for the possibility of viewing animals as speakers and even if the mechanics of speech and religion are borrowed from human sources, the ability to manipulate language in Malamud's fables seems not to imbue the animals who possess it with instant interiority, but to allow them to express preexistent inner selves which are variously, and particularly, primate, horse, and bird.

"The Jewbird" is probably the most "miraculous" of Malamud's animal fictions as in it the origin of Schwartz/Jewbird is neither questioned nor explained. The closest glimpse we see to the relation between his birdness and his seemingly "human" faculties is in an early explanation of how he prays: "The bird began dovening. He prayed without Book or tallith, but with passion. Edie bowed her head, though not Cohen. And Maurie rocked back and forth with the prayers, looking up with one wide-open eye. When the prayer was done, Cohen remarked 'No hat, no phylacteries?' 'I'm an old radical.' 'You sure you're not some kind of a ghost or dybbuk?' 'Not a dybbuk,' answered the bird, 'though one of my relatives had such and experience once. It's all over now, thanks God. They freed her from a former lover, a crazy jealous man. She's now the mother of two wonderful children.' 'Birds?' Cohen asked slyly. 'Why not?'" (323). This dialogue moves quickly to the point on a number of important issues for the story as a whole, issues both racial and specific. In terms of addressing the assumed divide between animality and reasoned faith, the story seems again to strike the tone of miraculous hybridity that marks Malamud's treatment of animals. The indication that Schwartz/Jewbird "prayed without Book or tallith, but with passion" places him in the family of what at least Cohen would consider an exclusively human faith, but also distances him from participation in "humaneness" in that the key element in his prayer is not the ability to read and participate in the Scriptures but his ability to access his (animal) "passions." At the same time, by describing Schwartz' motion as an act of "dovening," the narrator suggests through word play that the process of prayer and religious participation - at least in the world of the story - is something innately welcoming to bird participation, and welcoming to the expressions of religious expression that arise out of Jewbird particularities.

In terms of race and what Schwartz's position as a symbol for distinctly human racial politics suggests, the excerpt reinforces the claims of Watts and Hanson who suggest that key to the story is a narrative of Jewish self-hatred and uneasy US-Americanization. The response of the Cohen 
family, tentative and splintered, with the father not participating and the son's "one wide-open eye" suggesting that he is not sure what his proper reaction is supposed to be, indicate that the family is not completely comfortable with such a free and passionate expression of Jewishness, bird or human. Hanson, in his study of the story in relation to Poe's "The Raven," claims that for Malamud "After centuries of ethnic persecution and flight, and especially after Dachau and Auschwitz, [he] finds horror in the denial and suppression of one's ethnic self and all that the loss of that ethnic identity entails" (36). Following this path, and also consistent with the reaction shown above, Watts describes "The Jewbird" in terms of a model of Jewish "tenancy" in foreign locations: "After two thousand years of being tenants in other people's lands, in other people's cities, in other people's buildings ... Jews have come to internalize a tenant mentality: follow the rules, don't make waves, or you will be evicted" (157). To both the critical animal scholar and the defender of othered humans, it is obvious that oppressors - particularly oppressors of Jews - have long attempted to justify their mistreatments and often their violence by attributing what they considered a debased animality to Jewish populations. Therefore it is little surprise that although he himself is Jewish, Cohen's eventual mistreatments of Schwartz as a bird become Cohen's mistreatments of him as Jewbird, marking Schwartz's sufferings in solidarity with Jewish human experience. Indeed, Watts's larger argument is that the story conveys the destructive potentials of "Jewish self-hatred" revealed "in Malamud's treatment of Jewish immigrant as bird and tenant in an anti-Semitic Jewish community that is prospering (financially) in an anti-Semitic gentile environment" (159). At one point, Watts even notes Edie's realization of the irony of Schwartz being attacked by fellow crows (323). Such a structure explains the initial tentativeness of the family in an environment where the miraculous otherness of Schwartz and the unquestioning way in which he inhabits what he considers the naturalness of his being serves to highlight their own self-repressed identity as others.

At its moral core, "The Jewbird" is about opening up to otherness on two fronts: it is about giving compassion to the Other encountered through the miraculous circumstances of living and it also about opening oneself up to the fact that one's self is in some ways an Other, an understanding that will increase intrinsically the ability of one as a moral agent to recognize and sympathize with other marginalized people, human or not. And given the conventions of magical realism which underpin the story, rooted as they are in the responsive dialectics of historically othered communities, this actually makes for a fairly easy and affirming transition from accepting what might seem miraculous to most outside the community as normal to accepting that what might seem miraculous to most outside the community is normal. While Malamud's model is effective in its way and while the reader of his animal fiction is never made to forget the particular animalities of his non-human subjects, as they are always portrayed in the particularity of their species the need to convey their interiority through miraculous human speech and participation in human institution does have its limits. And this fact, I believe, is what makes it relevant to compare his work to Jin's. As Xiaojing Zhou contends, Jin's "writings break away from identity construction based on racial and ethnic differences," and instead of appropriating "predominant claims and strategies of identity politics, [he] insists on common humanity" (274). There is a strong emphasis, both in the body of critical literature on Jin and in the statements he has made about his own work that what most enables him to speak effectively for Chinese persons and Chinese immigrants to the United States is that he is not primarily interested in them as Chinese persons. That is, where Malamud seeks to promote solidarity and unity between persons by emphasizing their common participations and their ability to bridge and blend group identities, Jin seeks to emphasize commonality between groups and within groups by making their group identity a null point.

This is not to say that Jin does not recognize his subjects' identities as racialized and nationalized subjects. As Holly E. Martin notes, the collection from which "A Composer" is drawn, "Ha Jin's characters are often poor transmigrants who discover that they continue to be tied to China in restricting ways they did not anticipate, and also realize that they might never be accepted, because of their race in spite of their successes, as fully American" (1). Martin focuses on the ways in which A Good Fall flips the typical script of successful (im)migration and highlights that for those without the socioeconomic means to engage with dominant US-American society it is difficult to write for one's self a successful transnational script or that one's ability to form a fluidity 
of identity is often as connected to one's liquid assets as it is to one's ability to make effective spiritual, cultural, and social adaptations. Thus, in the stories of $A$ Good Fall specifically, Jin's focus is pointed primarily towards the domestic sphere and although his characters' transnational lives inform their socioeconomic circumstances, what is most pressing for them in the stories is not determining their position or self-actualizing themselves as Chinese Americans, but trying to figure out what to do after losing a job or negotiating a tough breakup. In this way, while Jin's model of cultural examination does account for the realities of racial and national politics, by focusing his stories on the lives of the underprivileged, Jin manages to present their nationalities as what they are: major factors in the situations they attempt to work through, but not the essential totality of who they are as persons.

The above brings us to the issue of language in Jin's work: in his own life and as a result in his stories Jin has been concerned with the power of language, specifically its use as a tool for political manipulation by the state. In explaining his decision to write in English as a Chinese immigrant/exile to the United States, Jin gave the following example to Sarah Fay, an interviewer for the Paris Review: "When the first emperor wanted to unify the country, one of the major policies was to create one system of written signs. By force, brutal force, he eliminated all the other scripts. One script became the official script. All the others were banned. And those who used other scripts were punished severely. And then the meanings of all the characters, over the centuries, had to be kept uniform as a part of the political apparatus. So from the very beginning the written word was a powerful political tool" (124). In other words, there was only one way to write Chinese and if there was only one way to write Chinese, then there was in a way only one way to be Chinese. Thus Chinese identity as determined by those in power was limiting and self-essentialized. Moreover, because the language "had to be kept uniform" by the state (Jin qtd. in Fay 124), it follows that the natural dialectic process of linguistic evolution, and by extension the evolution of thought in society, was suppressed. For Jin, this reality was obviously unacceptable and goes a long way towards explaining his decisions as both writer and citizen.

So what does all of this have to do with the birds? In "A Composer" - which, to note, Martin singles out as an exception to her reading of $A$ Good Fall as concerned with the underbelly of transnational migratory experience, mostly because of its auspicious conclusion - the concept of an aggressive insistence on the dominant language of those in power plays itself out in musician Fanlin's inability to understand the parakeet Bori's playing of the synthesizer after he first hears Fanlin working on a composition (11). Because Fanlin privileges human language, he fails to understand Bori's mimicry as a form of communication: at best, Fanlin treats the response as a solipsistic imitation with no meaning being expressed towards him. It is an annoyance, something not to be responded to but punished: "As Fanlin revised some notes, Bori alighted on the keys and stomped out a few feeble notes, which encouraged him to play more. "'Get lost!' Fanlin said. 'Don't be in my way.' The bird flew back to the desk, again motionlessly watching the man making little black squiggles on paper" (11). This is among the first instances of interspecies communication in the story and it serves mostly to highlight the initial unpreparedness of Fanlin to perceive the language of artistic expression as something that holds communicative value (he does not always end up treating Bori, or later Devin, so harshly). It has been for him, so far in his life, a commodity.

Much of Fanlin's initial withholding of any empathetic faculty from his art has to do with his relationship to his girlfriend, "A pretty Indian actress" named Supriya (9). The most important fact about her work, for Fanlin, is that it constantly takes her away from him: in fact, the way Fanlin initially comes into the stewardship of Bori, her pet parakeet, is that "Before departing for Thailand with her film crew," she "left [him] in Fanlin's care" (9). Thus in many ways Fanlin is portrayed as a kind of latchkey boyfriend, a commodity in his own right who provides companionship for Supriya when she is home and a convenient babysitter when she is away. This description is not to demonize her because the narrator makes it clear that she is also having to negotiate a difficult script as a transnational female actress, as in her words "her career would end before she was thirty-four," an obvious allusion to her own commoditization as a sex object in the film industry (9). In this way, both Fanlin and Supriya have developed a relationship to art that is mostly about money and loss and that under such circumstances it is difficult for Fanlin to compose or behave nearly as well as he could. But then Bori arrives, and as the narrator makes clear, the interplay 
between Fanlin and Bori comes to constitute the story's most fully actualized relationship. And although it might at first seem odd that a man's relationship to a parakeet would be more emotionally fulfilling than his relationship to his longstanding human partner, the facts start to seem a little less absurd the more the reader learns about the role of transience in Bori's and Fanlin's lives. In the first sentence of the story, at least four nations are alluded to: the nation of Thailand, the nation of Supriya's ancestral origin (India), the nation of Fanlin's ancestral origin (China), and the nation of the story's language and setting (the United States). The indication is that all of the three characters - Supriya, Fanlin, and Bori - are affected by the rigors of international travel, but as a matter of point it is only Supriya who is able to enjoy any of the lifestyle's rewards. Moreover, phrases from this sentence, including "left in Fanlin's care" and "inherited," suggest in the life of Bori a similar pattern of (im)migration and translocational identity formation to the human animals of the story. In this way, the bird's multi-owner history suggests a pattern of both transnational and coevolutionary adaptability (9).

It is adaptability and an ease of being in his situation that Fanlin does not share initially. For him, the situation he finds himself in with both Supriya and Bori brings about feelings of sexual insecurity: "Fanlin had never asked his girlfriend from whom, but he was sure that Bori, the bird, used to belong to a man ... Supriya must have had a number of boyfriends prior to himself" (9). Herein, Fanlin falls into the fear of a common script (cuckolding) of a competitive evolutionary model, reading Supriya's ability to move freely and his position as static caregiver as indicative of her sexual promiscuity and his social impotence and he then projects that script - that a woman will bed down and conceive with a more virile man, then hand the raising of the child off to a more docile, emasculated figure - onto his stewardship of Bori. Although there would seem to be little evidence that Supriya has been unfaithful in their relationship, it would seem that some of Fanlin's insecurities about his standing with her have legitimate foundations. The language used to describe their discussions of their status, for example, is characterized by phrases of displacement: it is said that Fanlin "might propose to her," but that that even in these mock proposals "He had hinted" at his intentions (9). And as previously noted, Supriya always rejects Fanlin's suggestions "either dodg[ing] the question or say[ing] her career would end before she was thirty-four" (9). Thus the relationship becomes for both partners a kind of holding pattern, something they are doing until something - although they cannot determine what - better comes along.

At first, this liminality feeds over into Supriya and Fanlin's treatment of their parakeet. As the reader learns in the first descriptions of the bird, "Fanlin wasn't very familiar with Bori, a small pinkish parakeet with a white tail, and he had never let the bird enter his music studio. Supriya used to leave Bori at Animal Haven when she was away, though if a trip lasted just two or three days, she'd simply lock him in the cage with enough food and water. But this time she was going to stay abroad for three months, so she asked Fanlin to take care of the bird" (9-10). There are a few more clues to Fanlin and Supriya's relationship in this paragraph: first, if Supriya has been in possession of Bori for an extended period of time, as her need to repeatedly figure out arrangements for him when she is has work would indicate and Fanlin and Supriya have been in a relationship for any considerable amount of time, then a) they have never considered or come close to a live-in relationship as a step between their current arrangement and marriage and/or b) they have had most of their interaction at Fanlin's apartment. But more importantly and more to the point as to how the story speaks of interspecies relations, it seems as if Bori is described as more of a logistical problem than as an individual or sentient being - everything from the fact that Supriya has "inherited" Bori (again, from a friend Fanlin assumes to be a former male lover, although that may or may not be the case) to the fact that Supriya is happy to leave Bori completely alone if she thinks the time period is short enough to the fact that her only consideration at those times is to make sure his physical needs are addressed with little consideration for the possibility of his loneliness or psychological wellbeing - indicating the assumption that Bori is an object, important so far only in his social transferability (9). Yet while this reading of the bird would seem to be consistent with his human owners' treatment of each other, it is a picture where Bori's actions begin to dismantle.

Bori's first reactions to Fanlin's music give at least some indication of his interiority. Before this, Fanlin "often wondered if he was dumb," given that "unlike some other parrots, Bori couldn't talk" 
(10) and "After breakfast, he let Bori into his studio for the first time. Fanlin composed on a synthesizer, having no room for a piano. The bird sat still on the edge of his desk, watching him, as if unable to understand the musical notes he was inscribing. Then, as Fanlin tested a tune on the keyboard, Bori began fluttering his wings and shaking his head. "You like my work?" Fanlin asked Bori. The bird didn't respond" (11). The easy move - and I think a wrong one - would be to read this passage as purely comic, as a scene of the bird's non-understanding silence meeting up serendipitously with the composer's bad work. What I think is truly going on in this scene is an episode of crosstalk with both Bori and Fanlin misunderstanding the ways the other is speaking and with Fanlin at least failing to recognize that the moment is conversational at all. It is important to note that Fanlin has made at least some step towards a a real relationship with Bori by allowing the bird into his studio, but one must also realize that the language of this scene and its ultimate dissemblance show that Fanlin is unwilling for this moment to exist on anything other than his own terms. When, for example, Fanlin asks Bori in human language "You like my work?" (11) there rests the possibility that he is in fact mocking the idea that the birds' reaction can be a form of real speech and communication and in this way what appears to be a communicative gesture may simply in fact a solipsistic dismissal of the bird's interiority. Fanlin and Bori are apparently unable to communicate in written language as shown by Bori observing Fanlin "as if unable to understand the musical notes he was inscribing" (11), although if we connect Bori's observation of Fanlin's "little black squiggles" (11) and connect that to the uninspiredness of the first half of Fanlin's rough composition, it may be possible to see Bori as understanding more than we might otherwise give him credit for. Still, as Fanlin and Bori are unable to connect through either human writing or through the aural symbology of human or parakeet language, they are left to communicate through the non-symbolic aurality of music. This is something which, apparently, Bori attempts to do, although Fanlin ultimately fails to recognize its significance.

What I posit above is not to say that Fanlin's treatment of Bori, as imperfect and clumsy as it was, was particularly cruel or abusive. In the totality of their relationship, Fanlin actually comes across as a pretty compassionate owner and although his occasional annoyances with the bird lead him to momentary lapses of kindness, the general tone of their domestic life is one of amiable, if limited, partnership. Take, for instance, this description of Fanlin and Bori sharing food: "Fanlin knew Bori liked millet; having no idea where a pet store was in Flushing, he went to Hong Kong Supermarket down the street and bought a bag. At times he'd give the parakeets what he himself ate: boiled rice, bread, apples, water, melon, grapes. Bori enjoyed this food. Whenever Fanlin placed his own meal on the dining table, the bird would hove beside him, waiting for a bite. With Supriya away, Fanlin could eat more Chinese food - the only advantage of her absence" (10). Or so Fanlin thinks. It is in this paragraph where we begin to see the affinity between Bori's and Fanlin's relationships to Supriya: it is not only Fanlin who finally gets to eat what he likes during her absence; rather, Bori seems to enjoy the availability of human food as well. And knowing that Fanlin does not know where a pet store is speaks here not so much to his non-participation in human/non-human relationships as it does to the kind of relationship he is looking to participate in in the first place - especially if we understand Fanlin's cohabitative sharing of food with Bori as caveating his refusal of Bori entering his music studio (14). Without the information we gain in this paragraph, it would be easy enough to assume that Fanlin refuses Bori because he rejects the bird outright or because he does not see him (or, through him, Supriya) as worthy of entering that place. And, considering the unspiritedness of the music we later find out that Fanlin composed while Bori was still alive (23), perhaps some of this is true. Still, in all of his dealings Fanlin seems to be obsessed with acquiring equal companionship with or respect from the world whether it is in his failed attempts to marry Supriya or his desire for respect from Elbert Chang or in his incompletely companionable relationship to Bori that leads to his deeper participation with the muse.

As to what happens after Bori's death - as, unfortunately, Bori passes away about half way through the story (21; an occurrence Fanlin mourns intensely, since in his mind "he had failed to save his friend" from the trauma he experienced after a boating accident described just before his death" [21]) - the easy assumption is that Fanlin could not compose emotionally in the presence of Bori because he did not truly care for Supriya and thus it was only the loss of his true love, Bori, 
who could inspire him (21). This is mostly true: Supriya was not Fanlin's true companion, but Bori was. However, saying that only the second half of Fanlin's composition refers to Bori risks making the relationship only an allegorical foil for the human relationship that preceded it. Moreover, it oversimplifies the story by making the problems of Fanlin's first draft signify that the first half represented false love while the second half represented true love (and loss). It is, in my opinion, more a case of Fanlin being unable to fully realize what he had with Bori until he lost it: in this way, instead of the first half of his composition relating to Supriya and the second half relating to Bori, both halves relate to Bori and show that it was the particular dynamics of how Bori and Fanlin lived together that informed Fanlin's passions. For, as we learn at the story's conclusion, it was not only Fanlin's relationship to Supriya that was ultimately unfulfilling. The human-bird dynamic Fanlin enjoyed with Bori was not transferable to his relationship with Devin, whom Fanlin "ignored ... entirely except to feed him" while he completed the musical score inspired by his lost friend (24).

Although I have little suspicion that Jin was consciously referencing "The Jewbird" when he composed the ending to "A Composer," it is in its cryptic unresolvedness typically Malamudian: "One afternoon, after working for hours, [Fanlin] was laying in bed to rest. Devin landed beside him. The bird tossed his long blue-tipped tail, then jumped on Fanlin's chest, fixing a beady eye on him. 'Ha wa ya?' the parakeet squawked. At first Fanlin didn't understand the sharp edged words, pronounced as if Devin were short of breath. 'Ha wa ya?' The bird repeated. 'Fine. I'm alright.' Fanlin smiled, his eyes filling. Devin flew away and alighted on the half-open window. The white curtain swayed in the breeze, as if about to dance; outside, sycamore leaves were rustling. 'Come back!' Fanlin called" (24). Although his ending cry indicates that Fanlin has not completely processed the lessons he has learned over the course of the story (and may not be completely aware, in fact, that it is his feeling for Bori that has allowed him to compose the way he has), it is also sure that Fanlin no longer needs to define and recapitulate relationships to fit easy terms marriage, pet/owner, etc. And because he has learned a lesson about love in its particularities from Bori, Fanlin does not need the easy anthropomorphic lessons that a "talking" bird like Devin might provide. In fact, having been given access to far less of the miraculous than was Cohen in "The Jewbird," Fanlin has managed to make a far greater opening of his emotional sympathies, to broaden his compassions in ways that the former man never could. Because of this, when Devin "flew away and alighted on the half open window" (24), language strikingly resonant of Schwartz's entrance to the Cohens' home, his departure is not one of a rejected tenant cast out into a violent world, but one of a spiritual teacher whose time has come to completion. Symbolically, this is an indication that the purely symbolic, magically real, and anthropomorphic symbologies of love are not quite so powerful, in the end, as the messy and imperfect partnerships that humans and nonhumans might actually enter into. What Schwartz's magic called for, Bori's realism demonstrated; and what Edie's recognition suggested, Fanlin's reciprocations (at least partially) fulfilled.

Note: I thank Jeff Saperstein (Radford University) and Holly Martin, Kathryn Kirkpatrick, and Jeanne Dubino (Appalachian State University) for comments on my article.

\section{Works Cited}

Adams, Carol J. Neither Man Nor Beast: Feminism and the Defense of Animals. London: Continuum, 1994. DeMello, Margo, ed. Teaching the Animal: Human-Animal Studies across the Disciplines. Brooklyn: Lantern, 2010.

Fay, Sarah. "Ha Jin: The Art of Fiction No. 202." Paris Review 191 (2009): 117-45.

Hanson, Philip. "Horror and Ethnic Identity in 'The Jewbird'." Studies in Short Fiction 30.3 (1993): 359-66.

Jin, Ha. A Good Fall. New York: Pantheon, 2009.

Jin, Ha. The Writer as Migrant. Chicago: U of Chicago P, 2008.

Kappeler, Susanne. "Speciesism, Racism, Nationalism ... or the Power of Scientific Subjectivity." Animals and Women: Feminist Theoretical Explorations. Ed. Carol J. Adams and Josephine Donovan. Durham: Duke UP, 1995. 320-52.

Malamud, Bernard. God's Grace. New York: Farrar, Straus and Giroux, 1982.

Malamud, Bernard. The Complete Stories. Ed. Robert Giroux. New York: Farrar, Straus and Giroux, 1997.

Malamud, Randy. "The Culture of Using Animals in Literature and the Case of José Emilio Pacheco." CLCWeb: Comparative Literature and Culture 2.2 (2000): <http://dx.doi.org/10.7771/1481-4374.1072>

Martin, Holly E. "Falling into America: The Downside of Transnational Identities in Ha Jin's A Good Fall." Transnational Literature 4.1 (2011): 1-11.

Varsava, Jerry A. "An Interview with Ha Jin." Contemporary Literature 51.1 (2010): 1-26. 
Watts, Eileen H. "Jewish Self-hatred in Malamud's 'The Jewbird'." Melus: The Society for the Study of the Multiethnic Literature of the United States 21.2 (1996): 157-63.

Zhou, Xiaojing. "Writing Otherwise than as a 'Native Informant': Ha Jin's Poetry." Transnational Asian American Literature: Sites and Transits. Ed. Shirley Geok-lin Lim, John Blair Gamber, Stephen Hong Sohn, and Gina Valentino. Philadelphia: Temple UP, 2006. 274-94.

Author's profile: Matt Prater teaches in the Smyth County School system of Virginia. His interests in research include transnational, Appalachian, and twentieth-century US-American literature. His creative work has appeared in The Hollins Critic and Now and Then: The Appalachian Magazine. <pratertm@email.appstate.edu> 